\title{
PERSPECTIVAS E ASPIRAÇÕES DO PROCESSO DO TRABALHO
}

\author{
PERSPECTIVES AND ASPIRATIONS OF LABOR PROCESS
}

Homero Batista Mateus da Silva*

\begin{abstract}
Resumo:
O presente artigo abarca as impressões do Autor a respeito da crise de efetividade do processo do trabalho, suas raízes históricas e a persistência de alguns vícios que impedem sua evolução. Demonstra a indispensabilidade da afirmação dogmática do processo trabalhista, dada a carga de peculiaridades que o afastam do processo civil. Narra a importância exagerada das interpretações jurisprudenciais para seu funcionamento, ante a escassez de dispositivos legais. Propõe, ao final, conjunto de medidas relativamente simples e urgentes capazes de alavancar sua prosperidade. $\mathrm{O}$ estudo, com pequenas alterações, corresponde à prova escrita que o Autor apresentou, com êxito, em concurso para o cargo de professor doutor do Departamento de Direito do Trabalho e Seguridade Social da Universidade de São Paulo.
\end{abstract}

Palavras-chave: Processo do trabalho. Celeridade. Efetividade. Interpretação. Alterações legislativas.

\begin{abstract}
:
The present article presents the author's impressions about the crisis of efficiency in Brazilian labor procedure law, including historical roots and the maintenance of some difficulties opposing its development. It comes as no surprise that labor procedure law should be kept aside from civil process, considering its large amount of subtleties. Moreover, a group of simple but urgent measures is sustained throughout the article as a meaning of effectiveness. This research, apart from some small details, evokes the examination the author successfully submitted to be accepted as a Professor of the Department of Labor and Social Security Law of the University of São Paulo Law School.
\end{abstract}

Keywords: Brazilian labor process. Brazilian labor procedure. Effectiveness. Interpretation. Legal reforms.

1. Aspectos das soluções dos conflitos trabalhistas

\subsection{Autodefesas}

Em busca de uma visão mais apropriada e abrangente do processo trabalhista, convém que se advirta a existência de abundantes formas de solução dos conflitos laborais que não coincidem com o exercício da tutela jurisdicional. Conquanto essa afirmação tenha sabor de lugar comum, é inegável a recorrência da autodefesa trabalhista mais do que se observa nos demais ramos do Direito.

Mestre e doutor em Direito do Trabalho pela USP. Professor Doutor do Departamento de Direito do Trabalho e Seguridade Social da Faculdade de Direito da USP. Juiz titular da $88^{\text {a }}$ Vara do Trabalho de São Paulo. 
A greve representa o exemplo clássico da autodefesa trabalhista e pode se gabar de notória evolução científica, numa rara hipótese que passou de delito a direito fundamental do trabalhador, assegurado em numerosos catálogos constitucionais e tratados internacionais. Maria do Rosário Palma Ramalho a insere no tripé que permitiu ao direito do trabalho sua plena afirmação dogmática, ao lado da negociação coletiva e da subordinação coletivo-pessoal do trabalhador em face do empregador. ${ }^{1}$

Outros exemplos, contudo, não devem ser desprezados, como lockout ou fechamento patronal, ainda que banido por boa parte das legislações; a sabotagem; o exercício do poder disciplinar imediato pelo empregador e assim sucessivamente.

\subsection{Autocomposições}

Nesse âmbito viceja a espinha dorsal do direito do trabalho, momento culminante das aspirações e dos anseios de empregados e empregadores. Pela via autocompositiva, os interessados têm a possibilidade de lavrarem convenções coletivas (alcance intersindical) e acordos coletivos (limite intraempresarial) com um efeito normativo que não encontra paralelo nos cânones do direito civil.

As normas coletivas costumam guardar o frescor da proximidade física e cronológica com os problemas do ambiente de trabalho e superam de longe a quantidade de leis que regem a matéria trabalhista com abstração e frieza. São incessantemente enaltecidas pela Organização Internacional do Trabalho como a forma mais adequada aos conflitos trabalhistas.

Dados os limites deste estudo, sejam apenas citadas outras formas de solução autocompositiva, designadamente o contrato coletivo interprofissional e os pactos sociais, ambos atrofiados na realidade brasileira. Para aqueles que incluem as formas unilaterais, como a submissão, entre os meios de autocomposição, cumpre lembrar o Termo de Ajustamento de Conduta, habitualmente celebrado pelo Ministério Público do Trabalho, o qual, desde o ano de 2000, adquiriu dignidade de título executivo extrajudicial trabalhista.

\subsection{Meios heterônomos}

Adota-se aqui a inserção de todas as modalidades de solução de conflito com a presença de terceiros entre os meios heterônomos, sejam os terceiros simples facilitadores ou dotados de poderes mais ou menos ativos.

RAMALHO, Maria do Rosário Palma. Da autonomia dogmática do direito do trabalho. Coimbra: Almedina, 2001. 
Justifica-se, assim, a referência à mediação, constante expressamente no art. 616 da Consolidação das Leis do Trabalho e art. 114, parágrafo primeiro, da Constituição Federal de 1988, mas, nada obstante, abandonada pela praxe trabalhista.

A arbitragem igualmente não encontrou o desenvolvimento esperado para as lides trabalhistas, o que se compreende talvez pelas fraudes generalizadas a que já se assistiu, talvez pela desconfiança que pesam sobre as instituições.

Referências legais não faltaram (Decreto-Lei n. 2.065/83, nunca implementado, Lei Orgânica do Ministério Público, Leis dos Portos, Lei da Participação dos Lucros), além de exortações da OIT, como a Recomendação n. 92.

Chega-se, assim, à tutela jurisdicional como meio heterônomo de solução do conflito, com seus vícios e suas virtudes. E para que a jurisdição atue concretamente, carece de um instrumento de ação de sua vontade, a que se chama de processo, sobre cujas peculiaridades se passa a tratar.

\section{Notas históricas}

Preliminarmente ao caráter científico do processo, vale lançar duas notas históricas.

A primeira objetiva lembrar que o direito processual nem sempre foi de legislação privativa da União (atual art. 22, I, da Constituição Federal), tendo os Estados federados mera competência concorrente para os procedimentos (art. 24, XI, Constituição Federal). Antes da Emenda Constitucional havida em 1926, a competência era das Unidades da Federação, o que justifica a existência dos conhecidos Códigos de Processo Estaduais e, na seara trabalhista, algumas experiências pioneiras como os Tribunais Rurais do Estado de São Paulo.

A segunda nota histórica almeja salientar o início tumultuado do processo do trabalho em geral e da Justiça do Trabalho em particular ter "pertencido" a estrutura do Poder Executivo por quase 20 anos (até a Constituição de 1946, ao menos formalmente) e ter sido marcada pela paritariedade (com presença de colegiado composto por juízes leigos em todas as instâncias, até a Emenda Constitucional n. 24, de 1999) deixaram marcas profundas na Justiça do Trabalho, talvez indeléveis.

3. Noções de processo e procedimento

3.1. Evolução científica

Os tratados da Teoria Geral do Processo aguardam um quase consenso de que a evolução científica do processo abarca quatro grandes fases: a) período de predomínio das teorias contratuais, creditadas a Pothier com algum subsídio em textos de 
Ulpiano, calcados no aspecto de negócio jurídico com submissão voluntária das partes ao processo; b) ênfase das teorias quase contratuais, que mantêm a natureza jurídica privada desta relação; c) o esplendor da virada do século XIX ao XX com os tratados de Bülow e a afirmação da teoria da relação jurídica, diferindo a relação jurídica processual da relação jurídica material, emancipando aquela perante esta; d) épocas das teorias críticas ao trabalho de Bülow, com destaque para Goldschmidt, que bem realçou a distinção entre ônus e obrigações e entre chances, expectativas e perspectivas, e para Elio Fazzalari, que lança luzes prioritariamente sobre o contraditório (processo como "módulos processuais") e a legitimação pelo procedimento.

Conforme enfatizado por Dinamarco e Grinover, as teorias mais recentes não desautorizam nem suplantam Bülow, mas complementam seu esforço em prol de uma relação jurídica processual autônoma. ${ }^{2}$

Para além das teorias sobre a natureza jurídica do processo, campearam estudos quanto aos momentos metodológicos bem demarcados entre (a) a fase imanentista ou sincrética do processo na plena dependência do direito material (a "visão plana do ordenamento jurídico" de que nos fala Dinamarco), (b) a fase autonomista sustentada nos estudos de Bülow e (c) o apogeu da fase instrumentalista, assumindo o processo seu papel de pólo irradiador de idéias e coordenador de institutos.

\subsection{Delineamento e escopos}

Postas essas premissas, delinea-se o processo como a síntese da relação jurídica progressiva, habitualmente apontado pela doutrina como o aspecto intrínseco da relação. É o instrumento da atuação da vontade concreta da lei, de que falava Chiovenda, ${ }^{3}$ na busca do "aquietamento justo da vida em concretude", como trata Manuel Alonso Olea. $^{4}$

Ao revés, o procedimento não é senão sua face visível, seu "aspecto extrínseco", na síntese feliz de Ada Pellegrini Grinover.

Embora seja comum associar procedimento com rito processual, é possível sustentar que este corresponde mais precisamente ao modo de ser daquele ou, antes, à forma legal de imprimir a marcha dos procedimentos.

Obviamente que nenhum desses termos há de ser confundido com meros autos, a forma palpável e materializada do processo judicial. Ainda que os autos pereçam, o processo segue o seu curso.

2 CINTRA, Antonio Carlos de Araújo; GRINOVER, Ada Pellegrini; DINAMARCO, Cândido Rangel. Teoria geral do processo. 24. ed. São Paulo: Malheiros Ed., 2008.

3 CHIOVENDA, Giuseppe. Instituições de direito processual civil. 2. ed. São Paulo: Bookseller, 2000. 3 v.

4 ALONSO OLEA, Manuel. Derecho procesal del trabajo. 8. ed. Madri: Civitas, 1995. 


\section{Afirmação dogmática do Processo do Trabalho}

\subsection{Persistência das teses monistas}

Passadas mais de oito décadas de justiça especializada e seis décadas de lei processual trabalhista, ainda remanescem teorias monistas a negarem a autonomia científica do processo do trabalho frente o processo civil.

Valem-se de alguns artifícios como o silêncio do art. 22, I, da CF, especificamente sobre "processo do trabalho", a falta de um Código Processual Trabalhista e, verdade seja dita, ausência de autonomia didática em muitas grades curriculares do bacharelado em direito.

Olvidam-se de que a afirmação dogmática de um ramo jurídico não se mede pelos parâmetros mais superficiais. Seguem-se comentários a essas críticas nos tópicos abaixo.

\subsection{Avanços das teses dualistas}

A inevitável aplicação subsidiária do processo comum ao processo do trabalho, fruto precípuo de desídia do legislador, leva alguns intérpretes a falar em autonomia relativa do processo laboral. A subsidiariedade, de que cuidam os arts. 769 e 889 da CLT, entretanto, não deveria impressionar, sendo essa uma técnica bastante usual nas normas de processo, dentro dos próprios Livros que compõem o CPC, e, ainda, no chamado microssistema de processo coletivo composto por Código de Defesa do Consumidor, Estatuto da Criança e do Adolescente, Lei de Ação Civil Pública e diplomas congêneres.

Destarte, a vasta matéria a ser abrangida pelo processo trabalhista, a verificação de doutrinas homogêneas, métodos peculiares e pautas reivindicatórias coesas permitem com muito mais equilíbrio a afirmação dogmática do processo do trabalho, tudo em companhia de Coqueijo Costa, ${ }^{5}$ Wagner Giglio, ${ }^{6}$ Manoel Antonio Teixeira Filho ${ }^{7}$ e caudalosa doutrina mundial.

Ainda que assim não fosse, convém reforçar a autonomia com pelo menos dez enfoques diferentes, abaixo frisados.

COQUEIJO, Costa. Direito processual do trabalho. 2. ed. Rio de Janeiro: Forense, 1984.

6 GIGLIO, Wagner Drdla. Direito processual do trabalho. 14. ed. São Paulo: Saraiva, 2005.

7 TEIXEIRA FILHO, Manoel Antonio. Execução no processo do trabalho. 7. ed. São Paulo: LTr, 2001. 


\subsection{Questões sobre a posição enciclopédica}

Antes dos esforços recrutados para a afirmação do direito processual do trabalho, é curioso notar que o consenso em torno da natureza pública do processo, tanto civil quanto trabalhista, costuma ser quebrado, vez por outra, por algumas vozes autorizadas, que se batem pelo reconhecimento da posição intermediária do direito do trabalho em geral.

Assim, colhe-se o ensinamento de Alberto Trueba Urbina, ${ }^{8}$ sobre a natureza jurídica do direito processual do trabalho como um direito reivindicatório, dentro do campo social, e de Alfredo Montoya Melgar," sobre a "tarefa inconclusa" do direito processual do trabalho ainda mais ligado ao trabalho do que ao processo.

\subsection{Singularidades frisantes}

As diferenças entre o processo civil e o processo do trabalho são inconciliáveis, pouco importando tempo de maturação dessa assertiva ou a demora para sua conscientização - aliás, entre seus próprios operadores.

Como elementos dessa separação dogmática, sejam realçados os seguintes aspectos:

Coletivização tendencial. Para além do poder normativo atribuído aos julgados coletivos dos tribunais, é interessante notar que o processo laboral sempre conviveu com formas próprias de demandas metaindividuais (ação de cumprimento, substituição processual variada, "ações plúrimas"), sem falar na advertência muito oportuna de Palomeque López ${ }^{10}$ no sentido de que quase todas as demandas trabalhistas são, na verdade, coletivas, pois repercutem no seio do ambiente de trabalho, em que vicejam causas análogas ou idênticas, esteja a litigiosidade contida ou não ("demandas pseudo-individuais", na linguagem do autor).

Formações litisconsorciais atípicas. É o caso da integração à lide do propalado empregador que não se enquadra em absolutamente nenhuma figura de intervenção de terceiros do Código de Processo Civil. ${ }^{11}$

TRUEBA URBINA, Alberto. Nuevo derecho procesal del trabajo. 3. ed. México: Editorial Porrúa, 1975. MONTOYA MELGAR, Alfredo [et. al.]. Curso de procedimiento laboral. 7. ed. Madri: Tecnos, 2005.

10 PALOMEQUE LÓPEZ, Manuel Carlos. Derecho del trabajo. Madri: Centro de Estúdios Ramón Areces, 1997.

11 É o que demonstra com propriedade a tese de doutorado de GARCIA, Gustavo Filipe Barbosa. Integração à lide na formação de litisconsórcio passivo ulterior: demandas sobre relação de emprego no processo do trabalho. 2007. Tese (Doutorado) - Faculdade de Direito, Universidade de São Paulo, São Paulo. 
Alta concentração de atos em audiência. Busca-se dar vazão para oralidade máxima, economia processual e celeridade. Reconheça-se que essa virtude do processo do trabalho é também seu fardo, pois as pautas de audiências longínquas põem tudo a perder.

Mera devolutividade recursal e características próprias para o reexame necessário. Há nítida influência dessa estratégia trabalhista no âmbito do processo civil. Cite-se a constante alteração do art. 520 do CPC e a restrição ao efeito suspensivo.

Foco na conciliação. Seguem obrigatórias duas tentativas de conciliação, em audiência, pela Consolidação das Leis do Trabalho. Mudança pontual na Constituição Federal objetivou apenas alcançar novas competências.

Distribuição dinâmica dos meios de prova. O processo laboral convive com a supervalorização da prova testemunhal (aquela que "sobra para o operário") em meio a técnicas de procura da melhor aptidão para a produção da prova, sendo casos paradigmáticos os fatos em torno de vínculo de emprego e exibição forçada de cartões de ponto (Súmula 338 do TST, tão amada quanto censurada). Há um sistema de presunções relativas muito bem alicerçadas nos princípios do direito material do trabalho (continuidade da relação, proteção, irrenunciabilidade, primazia da realidade, razoabilidade e boa-fé, na célebre classificação de Américo Plá Rodrigue $^{12}$ ), sem paralelo nos demais ramos jurídicos e com grande repercussão processual e procedimental.

Maiores poderes ao Juiz. Impulsos de ofício, que já eram realidade nos primórdios em termos de execução trabalhista e demandas ajuizadas pelo próprio empregado, foram exacerbados com a obrigação de cobrança ex officio das controvertidas contribuições previdenciárias decorrentes das sentenças e acordos trabalhistas.

Resistência da capacidade postulatória às partes. Com aval do Supremo Tribunal Federal, permanece a possibilidade de se prescindir de advogado com a movimentação do processo pela própria parte. Utópica ou não, a capacidade postulatória afeta diversas posições processuais, a começar pela atrofia do sistema de honorários de advogados. Note-se, também, a remanescência do sistema de custas pelo "vencido", sem a noção da sucumbência recíproca e com grande desenvolvimento do tema da assistência judiciária gratuita.

12 PLÁ RODRÍGUEZ, Américo. Principios de direito do trabalho. 3. ed. São Paulo: LTr, 2000. 
Catálogo próprio de títulos executivos judiciais e extrajudiciais. O rol se mostra tendencialmente taxativo (art. $876 \mathrm{da}$ Consolidação das Leis do Trabalho).

Decisões marcadas pela extrapetição. Com apoio expresso ou velado da lei, os julgados estão livres para dizerem o direito sem maior apego à petição inicial. Servem como exemplos a alternância entre reintegração do empregado ao emprego ou sua conversão em pecúnia (art. 496 da Consolidação das Leis do Trabalho) e a ordem de registrar o contrato de trabalho documentalmente (art. 39 da Consolidação das Leis do Trabalho), independentemente dos pedidos.

5. Impactos do "direito jurisprudencial" no processo do trabalho

O perfil do processo do trabalho fica incompleto, desfigurado e desatualizado se o estudo não enfrentar o assim chamado "direito jurisprudencial” (Mauro Cappelletti $\left.{ }^{13}\right)$.

Conquanto cuidando de temas adstritos ao controle de constitucionalidade, Canotilhoigualmenterefereaoassuntosobadenominaçãode "positivismojurisprudencial". ${ }^{14}$ No processo do trabalho, temas como esses não podem ser mais urgentes.

Largos espectros do processo estão completamente ausentes das normas postas e abarcados na totalidade pelos verbetes do Tribunal Superior do Trabalho.

À constelação de Súmulas (agora com incisos e parágrafos) agregam-se as chamadas Orientações Jurisprudenciais, que, superexploradas, já se dividem em cinco blocos (dissídios individuais, competências originárias, uso restrito ou regional, dissídios coletivos e orientações plenárias). As diretrizes processuais e procedimentais são contadas às centenas.

Tome-se a Súmula 331 como exemplo.

Além de ser um raro norteamento ao regime de terceirização trabalhista no Brasil, a Súmula 331 praticamente criou uma forma anômala de litisconsórcio passivo e atribuiu a responsabilidade patrimonial subsidiária ao beneficiário dos serviços, a que denominou tomador.

Pela delimitação do espaço, basta por aqui evocar, outrossim, os curiosos exemplos da pesada restrição que se abateu sobre a substituição processual via Súmula 310, que foi cancelada por força de decisões do Supremo Tribunal Federal; da complexa rede de solidariedade muito mal resolvida com o cancelamento da Súmula 205 acerca dos

13 CAPPELLETTI, Mauro. Juizes legisladores? Porto Alegre: Sergio Antonio Fabris Editor, 1999.

14 CANOTILHO, José Joaquim Gomes. Direito constitucional e teoria da Constituição. 4. ed. Coimbra: Almedina, 2000. 
conglomerados econômicos; e a surpreendente decisão de adotar o art. 93 do Código de Defesa do Consumidor para fixação de critérios de competência das ações metaindividuais (Orientação Jurisprudencial 130 da Subseção II da Seção Especializada em Dissídios Individuais do Tribunal Superior do Trabalho).

Cappelletti, em seus conhecidos estudos sobre o acesso à justiça, não demoniza o "direito jurisprudencial", mas adverte quanto aos riscos da (a) dificuldade de informação, (b) eficácia retroativa exagerada, e (c) incompetência institucional, sendo esse item associado ao caráter anti-democrático do direito sumular. ${ }^{15}$

6. A crise de identidade do processo do trabalho e os transtornos da "hipertrofia asseletiva"

O processo do trabalho parece não ter se orgulhado dos instrumentos de que sempre dispôs para a solução dos conflitos e os deixou atrofiar. $\mathrm{O}$ caso da vedação à substituição processual sindical ampla, quando da existência da Súmula 310, de 1993 a 2003 , já se tornou célebre. Exportou-se bastante tecnologia para o processo civil (coletivização, gratuidade, especialização, celeridade) e se importaram apenas os problemas (morosidade e, claro, os recursos, muitos recursos).

Acrescentando insulto à injúria, o processo do trabalho acaba de receber pesada incumbência de lidar com dezenas de "novas competências", oriundas da Emenda Constitucional 45, a qual, conquanto date de 08/12/2004, ainda não se acha plenamente implantada.

São suficientes as lembranças dos seguintes temas: a) execução de multas administrativas impostas pela fiscalização do trabalho; b) ações dos representantes comerciais autônomos com as peculiaridades processuais inerentes à Lei n. 4.886/1965; c) milhares de ações com pedidos de indenização por danos morais e materiais decorrentes de acidentes e doenças ligadas ao labor, que pareciam adormecidas.

Nada mais se constata do que o desembarque, no processo do trabalho, da "hipertrofia asseletiva", de que nos fala Salvo Leonardi, ${ }^{16}$ por que passa o direito do trabalho. No afã de querer abraçar todas as causas e agasalhar todos os interesses ligados às atividades produtivas colidentes ou não, corre-se o risco de não se atender adequadamente a ninguém.

A hipertrofia deu ensejo, também, ao crescimento alarmante dos assim chamados "litigantes habituais". Cappelletti igualmente se debruçou sobre o fenômeno e, como que sabendo das aflições da Justiça do Trabalho brasileira, traçou o perfil do litigante

\footnotetext{
15 CAPPELletTi, Mauro. Acesso à justiça. Porto Alegre: Sergio Antonio Fabris Editor, 2002.

16 LEONARDI, Salvo. Globalizzazione e relazioni industriali. Roma: Ediese, 2003.
} 
habitual como sendo aquele que (a) procura "economia de escala" às custas do processo judicial, (b) elabora planejamento de longo prazo, (c) mantém relações informais com os frequentadores das cortes trabalhistas, o que inclui, perigosamente, Juízes e servidores, (d) dilui custos da sucumbência e (e) pode testar estratégias de uma tese jurídica em processos de menor complexidade antes de atingir os de maior envergadura.

Daí à procrastinação dos feitos e à curiosa figura do "assédio processual" (meio ardiloso de forçar acordos em bases modestas sob a ameaça de um processo infinito) foi apenas um passo.

Não era bem isso que a ciência processual objetivava alcançar.

\section{Perspectivas e aspirações}

As angústias acima descritas não são nem exclusivamente processuais nem apenas trabalhistas, se isso serve de consolo. Decorrem de causas múltiplas que vão desde a complexificação da sociedade até o próprio incentivo de maior e mais qualificado acesso ao Judiciário. Por óbvio que não se resolvem problemas judiciários represando a litigiosidade, assim como não se abrem leitos hospitalares eliminando-se pacientes.

Assistir a essa degeneração de forma passiva, todavia, é conduta inesperada de qualquer operador ou estudante de direito.

Com apoio nas lições de Tércio Sampaio Ferraz Junior, citando Hans Girardi na obra "Despedindo-se de Montesquieu", ${ }^{17}$ bem assim na vasta colaboração de Mauro Cappelletti, ${ }^{18}$ pode-se conceber que os anseios do processo do trabalho passam pelas seguintes estratégias:

Aceleração de reformas legislativas. As reformas são necessárias, mas sabidamente insuficientes. Destaque para regulamentação do ignorado fundo de garantia das execuções trabalhistas, contemplado pela própria Emenda Constitucional 45 e, ato contínuo, desdenhado, e para um rearranjo à confusa situação do art. 769 da Consolidação das Leis do Trabalho: cada vez que o processo civil adquire medida célere ou criativa, como a multa de $10 \%$ do art. $475-\mathrm{J}$ ou a citação na pessoa do advogado, voltam as divergências sobre o caráter ontológico e axiológico da subsidiariedade do processo comum. Já há mesmo quem propugne a revogação completa dos artigos 643 a 910 da Consolidação das Leis do Trabalho para pôr fim à discórdia.

\footnotetext{
17 FERRAZ JUNIOR, Tércio Sampaio. O Judiciário frente a divisão dos poderes: um princípio em decadência? Revista Trimestral de Direito Público. São Paulo, n. 9. p. 40-48, 1995.

18 CAPPELlETTI, Mauro. Acesso à justiça. Porto Alegre: Sergio Antonio Fabris Editor, 2002.
} 
Valorização dos meios alternativos de solução dos conflitos. Os esforços de Cappelletti neste sentido, porém, foram duramente golpeados pelo excesso de fraudes e desvirtuamentos vivenciados pelo direito do trabalho em tempos recentes, havendo pouca esperança para a aplicação de procedimentos de mediação e arbitragem no direito individual do trabalho, no curto prazo. A tragédia das Comissões de Conciliação Prévia foi apenas o exemplo mais atual. Criadas em 2000, sua revogação completa já consta do Projeto de Lei conhecido por Reforma Sindical.

Especialização de Varas e de Turmas. Eis um caminho eficiente e pouco utilizado pelo processo do trabalho, que adquire caráter de urgência. Uma excelente oportunidade seria tomar carona no Anteprojeto do Código Brasileiro de Processo Coletivo, de co-autoria de Ada Grinover, que exorta justamente a especialização como forma de incremento da prestação jurisdicional e realça o processo como "fenômeno social de massa". ${ }^{19}$

Desneutralização do Poder Judiciário. Aquilo que já se verificava pela civilização tecnológica assume nova dimensão para a reconfiguração das funções institucionais da magistratura.

Barreiras jurisdicionais não caem uma a uma nem seguem uma lógica de superação previsível ou calculável.

Mas é preciso insistir.

São Paulo, maio de 2009.

\section{Referências}

ALONSO OLEA, Manuel. Derecho procesal del trabajo. 8. ed. Madri: Civitas, 1995.

CANOTILHO, José Joaquim Gomes. Direito constitucional e teoria da Constituição. 4. ed. Coimbra: Almedina, 2000.

CAPPELlETTI, Mauro. Acesso à justiça. Porto Alegre: Sergio Antonio Fabris Editor, 2002. . Juizes legisladores? Porto Alegre: Sergio Antonio Fabris Editor, 1999.

CHIOVENDA, Giuseppe. Instituições de direito processual civil. 2. ed. São Paulo: Bookseller, $2000.3 \mathrm{v}$.

19 GRINOVER, Ada Pellegrini; MENDES, Aluisio Gonçalves de Castro; WATANABE, Kazuo. Anteprojeto do código brasileiro de processo coletivo. São Paulo: Revista dos Tribunais, 2007. 
CINTRA, Antonio Carlos de Araújo; GRINOVER, Ada Pellegrini; DINAMARCO, Cândido Rangel. Teoria geral do processo. 24. ed. São Paulo: Malheiros Ed., 2008.

COQUEIJO, Costa. Direito processual do trabalho. 2. ed. Rio de Janeiro: Forense, 1984.

FERRAZ JUNIOR, Tércio Sampaio. O Judiciário frente a divisão dos poderes: um princípio em decadência? Revista Trimestral de Direito Público. São Paulo, n. 9. p. 40-48, 1995.

GARCIA, Gustavo Filipe Barbosa. Integração à lide na formação de litisconsórcio passivo ulterior: demandas sobre relação de emprego no processo do trabalho. 2007. Tese (Doutorado) - Faculdade de Direito, Universidade de São Paulo, São Paulo.

GIGLIO, Wagner Drdla. Direito processual do trabalho. 14. ed. São Paulo: Saraiva, 2005.

GRINOVER, Ada Pellegrini; MENDES, Aluisio Gonçalves de Castro; WATANABE, Kazuo. Anteprojeto do código brasileiro de processo coletivo. São Paulo: Revista dos Tribunais, 2007.

LEONARDI, Salvo. Globalizzazione e relazioni industriali. Roma: Ediese, 2003.

MONTOYA MELGAR, Alfredo et. al. Curso de procedimiento laboral. 7. ed. Madri: Tecnos, 2005.

PALOMEQUE LÓPEZ, Manuel Carlos. Derecho del trabajo. Madri: Centro de Estúdios Ramón Areces, 1997.

PLÁ RODRÍGUEZ, Américo. Princípios de direito do trabalho. 3. ed. São Paulo: LTr, 2000.

RAMALHO, Maria do Rosário Palma. Da autonomia dogmática do direito do trabalho. Coimbra: Almedina, 2001.

TEIXEIRA FILHO, Manoel Antonio. Execução no processo do trabalho. 7. ed. São Paulo: LTr, 2001.

TRUEBA URBINA, Alberto. Nuevo derecho procesal del trabajo. 3. ed. México: Editorial Porrúa, 1975. 